\title{
TURNING A NEGATIVE INTO A POSITIVE WITH MODERN ELECTRONIC TECHNOLOGIES
}

\author{
Michael Piczak, Project Manager, Energy Research Programs \\ Mohawk College \\ mike.piczak@mohawkcollege.ca
}

\author{
Dr. N. Al-Mutawaly, \\ Professor, Electrotechnology, Mohawk College \\ nafia.almutawaly@mohawkcollege.ca
}

\begin{abstract}
In today's society, electronic devices represent an important part of the cultural fabric, especially for the younger generation. Professors and lecturers teaching at post-secondary levels express concern when students appear to be more interested in electronic devices than the content being presented in the classroom. These devices permit the student to locate small snippets of data and information leaving them largely incapable of integrating this data into comprehensive concepts. Another drawback of using modern electronic devices in the classroom relates to their misuse during examinations. The argument from an educator's perspective is: suppression versus celebration, as electronic devices assume a ubiquitous place and role in the classroom. Unable to effectively compete with the apparent entertainment value of iPods, iPads, cell phones and laptops, educators and policy makers enact a range of measures designed to enforce student engagement during class time. Institutional responses to the use of electronic devices include: policy language enshrined in course outlines, bans on such devices and confiscation of offending devices. Conversely, given that every conceivable subject is available via the internet, these electronic tools are effective in 'bringing the world into the classroom'. This paper explores and presents actionable strategies that educators can employ to leverage the power of electronic devices in stimulating students' participation during classroom delivery. Based on literature search, personal experience and field interviews, suggested best practices are advanced for the enhancement of the learning environment (both lecture and lab) in the pursuit of improved learning outcomes. The paper will also present the limitations and drawbacks in the use of these devices.
\end{abstract}

Keywords: digital devices, mobile, pedagogy, student distraction, time on task, world in the classroom

\section{INTRODUCTION}

Electronic mobile devices, namely cell/smart phones, mp3 players, tablets and laptops have firmly attached themselves to the younger generation (Gen Z), often 24 hours a day. Such devices make their way into the classroom setting as a matter of habit, bordering on addiction. The challenge for educators is how to compete with the information and data that these devices make available at the touch of the fingertip. Were the stream of data being downloaded relevant to the discussion unfolding in class, there would be less of a concern.

Curriculum and course planners often speak in terms of "bringing the world into the classroom" as a means of bridging the gap between academe and the environment students will join upon graduation. To the extent that one could leverage the electronic device as a way to locate and access the constellation of knowledge available on the internet, these devices can deliver limitless possibilities by uncovering otherwise unrealized connections, relationships and nuance.

Most educators perceive pressure from such 'cool' devices with the foregone conclusion there is little that can be done to compete against the information and entertainment value of electronic devices. As a means of fighting back and mandating attention, resort is made to rules specifying conditions under which such devices can be permitted in the classroom. Initial and kneejerk reactions invoke outright bans, device confiscation and restrictive policies adopted by the professor, department or institute. Many such policies can easily be accessed online. More forward thinking administrators and educators, however, consider options that leverage the power of such devices.

This paper provides a number of actionable strategies and options available to the educator who faces the prospect of knowing that on any given day in class, they will not fare well relative to an electronic mobile device. 


\subsection{BACKGROUND}

Electronic devices of the personalized variety have a lineage going back almost 40 years dating to the introduction of personal computers with the Apple 1 (1976) and IBM XT PC (1981). Mainframe computing was left behind in gymnasium sized complexes in favour of desktop and personal computing. Miniaturized devices heralded a new world where the population learned about DOS, C prompts, autoexecute files for booting up machines, computer crashes, software suites for word processing (SAMNA, Wordstar and WordPerfect) and spreadsheets (Visicalc, Lotus 1-2-3).

By the early 1990s, Apple had created the Newton tablet, early adopters exchanged the first emails, computing power grew, cost per byte processed went down, device size continued to shrink, green/amber screens were replaced with VGA colour monitors and first generation laser printers were $\$ 5,000$.

The 1990s saw the internet become increasingly adopted for commerce and data transfer with Lynx, www, the killer app Mosaic, Netscape and finally, Internet Explorer by 1995 . The new millennium welcomed Mozilla, Safari and later on, Chrome.

Continued evolution and refinement of hardware and wireless technologies converged with software developments to produce data and information access heretofore unknown to mankind. The dot com revolution of the late 1990s can serve as a prime illustration of these technologies' convergence.

The population in general and Gen $\mathrm{Z}$ in particular have grown up within this new digital normal where staggering quantities of computing and information power are a click away. Among college students, studies show the average student owns 6.9 devices with penetration/adoption varying by device: cell/smart phone $90 \%+$, laptops $85 \%$, tablets $36 \%$, computer games, e-readers and $\mathrm{mp} 3$ players finding their way to one third of the student population [1]. As the $21^{\text {st }}$ century has unfolded, these devices have become omnipresent particularly with the younger generation that grew up with digital technology being commonplace. The device and technology adoption trend is not likely to change any time soon as captured in Table 1 .

Table 1: Device Growth Predictions [2]

\begin{tabular}{|l|c|c|c|}
\cline { 2 - 4 } \multicolumn{1}{c|}{} & $\mathbf{2 0 1 2}$ & $\mathbf{2 0 1 7}$ & \% Growth \\
\hline Internet users & 2.3 billion & 3.6 billion & $56 \%$ \\
\hline $\begin{array}{l}\text { Global devices or } \\
\text { connections }\end{array}$ & 12 billion & 19 billion & $58 \%$ \\
\hline Internet video users & 1 billion & 2 billion & $100 \%$ \\
\hline
\end{tabular}

Compactness and apparent necessity made it inevitable that these devices would make their way into the classroom setting up the tension between teacher as educator and the device as entertainer/distracter. In this age of modern media distraction, teaching and mentoring represents a genuine challenge for both educators and students, although the latter may not realize it.

Undergraduates and graduate school candidates in today's classrooms are far different from the student body that educators represented when they went through school. Black rotary phones and punch card readers would have been the norm in days gone by. Having passed through the PC transition of the 1980s, society and academe have evolved along this technological journey some adapting better than others. Regretfully, educators may be falling behind with the proliferation of devices where digital capabilities stretch beyond the imaginations of most futurists. One can only imagine the class of the mid millennium.

\subsection{THE CLASSROOM CHALLENGE}

Today's student can be found to routinely carry around laptops, smart phones and an mp3 player as a matter of urban survival on a day to day basis. These devices provide instant access to the users, others and virtually all the data and information produced to date by mankind.

This same student has grown up with less interest to read, obtains information in ways different from their parents' generation (internet, messaging) and seems to be lacking in the discipline necessary to delve into issues. Snippets of information pass for knowledge and education with the integration of data viewed as a chore particularly where deeper understanding takes time and effort. Attention spans appear short in the pursuit of instant gratification as provided by Instagram, Facebook and other social media outlets. In a word, Generation Y is more easily 'bored'.

This combination of surfing-for-information mentality, vulnerability to boredom and the search for immediate gratification serve to set up a challenge for the well intentioned educator armed only with facts, formulas and the threat of tests, examinations and failure in an effort to triumph over this entertainment driven conspiracy.

Understanding technologies and their appeal to students would assist in devising educational content and process that can move student attention from entertainment seeking to knowledge thirsting, all of this facilitated by the educating professor. 
To deal with the distraction circumstance, the educator relies on tried and true factors that work in the face-to-face classroom. A constellation of academic achievement predictors within the traditional classroom have long been identified across many studies and elevated to the level of mantra. A selective list of positive academic achievement correlates include: self efficacy, personal life factors, time on task, vocational intent, collegiate career centers, co-op, tutoring and class size [3 - 5].

Using meta analytic methods, Bloom summarized the empirical research that has come to be known as the 2Sigma problem. In a seminal paper [6], Bloom set out twenty factors as contributing to improvement in student success. Tutorial instruction as an independent factor contributed two standard deviations of improvement while one sigma improvements were delivered with reinforcement, corrective feedback, cues and explanations, classroom participation, improved reading skills and time on task.

Time on task has long been discussed as a primary factor contributing to academic achievement [7]. Where electronic devices are used to advantage, time on task is increased. Conversely, time spent surfing the internet, texting or anticipating the next communique erodes time spent on the task at hand.

\subsection{DIGITAL DEVICES: BENEFITS/CONCERNS}

Today's student retrieves information in ways their professor never considered possible. At the risk of generalizing, most students are not digitally aligned with their professors particularly educators who hold senior ranks. While engaged in learning and acquiring knowledge, students prefer to do so by interacting with technology in the same way their professors were engaged by books and journals found in the stacks. Students wake up (apparently over $80 \%$ sleep with a device at their side) and function by interacting with their beloved devices and the challenge is to make use of technologies that many academics are largely (and increasingly) unfamiliar with.

Electronic devices present tremendous advantages for students by enhancing the academic environment when device capability is leveraged to aid the learning process. Mobile, digital devices are capable of: enabling notetaking, instantly accessing history/background/proofs, providing demonstrations, performing calculations, plotting data, presenting with novel tools (Prezi and 3D timeline software) [8,9], accessing open courseware (Khan Academy) [10], engaging with polling capability (clickers), digitally capturing board notes (Smart Boards), podcasting for on-the-run learning, testing students via mobile devices and communicating with professors/TAs.

For educators, electronic devices have the potential to promote engagement, improve student attitudes towards their studies and elevate student learning. Rather than relying on a single individual in the room to have all the answers, classrooms can have scores of sages helping the student body and professor to locate, consider and discuss issues with the aim of achieving profound knowledge. Along the way, it may even be possible to enjoy the road to comprehension by making effective use of electronic devices.

Notwithstanding the benefits associated with mobile digital devices, a spectrum of concerns present themselves leading educators to consider various levels of restriction and prohibition on laptops/tablets and phones. In the view of educators, such devices distract during classroom settings and facilitate the degradation of the research and thinking process outside the classroom [11].

On the other hand, students are of the firm belief that they are excellent multitaskers or parallel processors, yet, research informs otherwise. In the classroom, students make resort to devices for gaming, facebooking, watching unrelated videos, and text messaging. The prospect of a missed call or text seems synonymous with digital withdrawal in case some questionably relevant message is not immediately retrieved. Taken together, students expend more time on distractive data streams than they do on relevant information, underreport device use and have poorer grades to show for it [12-15]. Recent in-class experiments demonstrate the negative impact that devices can have on student performance [16].

Another source of major concern relates to plagiarism and academic dishonesty, where students knowingly or otherwise locate information via the internet and present the same as their own. In addition, during testing situations, devices can be employed for ill intentioned purposes including exchange of text messages, accessing servers for information/uploaded notes, photographing test questions and awaiting expert response, and digitizing exam questions for future use. The unprepared, unable and digitally savvy student is capable of all manner of academic dishonesty in their quest to obtain a degree.

As a matter of defending academic integrity, educators respond with plagiarism detecting software, limit calculator/smart phone use in examinations, craft conditions under which devices can be permitted and have academic advisors remind students as to distractive powers of digital devices. 


\subsection{TOOLS AVAILABLE TO EDUCATORS}

The point of departure for the educator is to recognize and acknowledge that today's student is decidedly different from days gone by. From JK to university, twelve plus years of intensive conditioning and functioning with these devices, along with not having learned when it is appropriate to operate them, sets the actors in this scenario on a collision course when student meets post secondary education.

In the same way that students utilize digital devices to apparent advantage, so too can educators in the fight to win the hearts and minds of Gen $\mathrm{Z}$ and beyond. It is incumbent upon the educator to identify current and leading edge technologies to enhance the overall student learning experience. Rather than declare an all-out war on digital devices, it is recommended that academics consider ways and means of utilizing current and emerging technologies to advantage.

It is possible to consider the adaptation of digital technologies to various elements of the pedagogical enterprise by breaking course preparation and achievement of learning outcomes into discrete components and offering suggestions for each stage. Such categories of pedagogical endeavor might be captured as follows: preclass, in-class, post-class and assessment tools.

\subsection{Pre-Class}

Learning management systems (LMS) have been part of the educational landscape for some number of years lending themselves to both delivery of learning content and course administration. Universal remote access permits students to learn at their convenience regardless of place and time. LMSs have become standard equipment at virtually all levels of education with companies such as Blackboard, Moodle and Desire2Learn representing the majority of the educational market. Such technologies are ideal for handling/delivering content, showcasing student capabilities via e-portfolios, administering/grading tests and finally, recording test and assignment results. Administratively, LMSs excel at providing academic scorecards, communicating with students, dispensing triggered content, broadcasting announcements and keeping students on task/track.

Content provided before class moves the educator in the direction of the flipped classroom permitting class meetings to be problem solving sessions along with opportunities for active learning. To the extent that students can be overwhelmed with course learning resources, educators must be mindful of the overall student capacity to absorb material.

\subsection{In-Class}

The digital challenge plays out in the classroom/lab with students wanting to engage their device while the educator looks to engage the student. A selection of relatively simple strategies can be employed to advantage including:

- Using modern digital technologies to capture students' attention and interest

- On-line access to course materials, assignment and projects during lecture/lab

- Assigning truth and fact checking duties to students

- Use digital devices for labs, field experiments, simulations and presentations

- Remote lecture delivery via Skype or synchronous tools (Webex, Collaborate, Saba Centra)

- Using clickers/polling along with the mobile device

\subsection{Post-Class}

Profound learning begins after the classroom session where students on their own time reflect on the selection of LMS delivered content along with happenings in the flipped classroom. To reinforce material, students can be afforded all manner of resources as follows:

- Providing a set of complete notes on line such that students can compare their prepared notes against notes that would deliver an ' $\mathrm{A}$ '

- Sharing a set of comprehensive notes as provided by students for comparison purposes

- Providing access to lecture capture, digital smart board uploads or Camtasia produced videos

- Providing recording links for synchronous classes

\subsection{Student Assessment}

Digital devices lend themselves to the delivery of on-line evaluation and delivering/managing on-line assignment submissions. Higher end LMSs often allow for audio feedback inviting the professor or TA to individualize/personalize comments thereby strengthening the evaluator/student connection. Specific feedback permits students to improve in particular ways elevating performance. Providing students with research findings on the distractive capabilities of electronic devices permits students to come to their own realization as to the drawback of misusing devices during class time.

\subsection{The Future Classroom}

The previous discussion has presented issues, concerns and suggestions based on the traditional face-to-face 
classroom, with average student enrollment reported to be 255 at the University of Toronto [17]. On the other hand, Massive On Line Courses (MOOC) class sizes can average in the tens of thousands. The prospect of MOOC style and on-line blended courses presents unique learning challenges given the unsupervised nature of such deliveries. Multitasking with no one other than a streamed video to keep the student on task means that there may be even less attention paid to the content being delivered 'in class'. In conclusion, the distance education environment, of necessity, shifts responsibility for learning in the direction of the student in the absence of a professor to monitor behavior. The on-line/MOOC student must demonstrate the discipline necessary to achieve learning outcomes.

\subsection{CONCLUSIONS \& RECOMMENDATIONS}

This paper has attempted to equip the university professor with an array of ideas that can help to turn students' attention to what is being discussed in class away from that which is streaming in over their devices. The digital revolution is alive and well in the classroom and lab with no apparent sense that it is letting up any time soon. The wise and leading edge professor is the one that capitalizes on the use of these technologies even in limited modalities. Educators need to get digitally on board otherwise placing at risk the ambition to fulfill the expectations of Gen $\mathrm{Z}$.

To avoid such a situation, it is recommended that educators:

1. Use TAs to develop digital course materials

2. Stay close to and force technology adoption upon themselves

3. Introduce and integrate digital technologies into lab and course work to demonstrate the advantages of these devices

4. Adopt a contingency approach to the use of traditional delivery approaches in combination with digital technologies

5. Craft flexible digital technology use policies that permit the instructor to recognize and permit device use in the classroom to meet course requirements

6. Enforce strict policy to prevent device misuse specifically related to academic dishonesty

It is the goal that even if one of the presented suggestions makes a difference in the classroom, then a pedagogical contribution will have been made anemic as such an ambition may sound on first blush. The future is digital and it starts now.

\section{REFERENCES}

[1] http://www.marketingcharts.com/wp/online/collegestudents-own-an-average-of-7-tech-devices-30430/

[2] http://newsroom.cisco.com/release/1197391/

[3] Hein, V., Smerdon, B., Sambolt, M., Predictors of Post Secondary Success, American Institutes for Research, 2013.

[4] Almaraz, J., Bassett, J., Sawyer, O. (2010). Transitioning Into a Major: The Effectiveness of an Academic Intervention Course. Journal of Education for Business.

[5] Breso, E., Schaufeli, W.B., Salanova, M. M. (2010). Can a self-efficacy-based intervention decrease burnout, increase engagement, and enhance performance? A quasiexperimental study. Published with open access at Springerlink.com.

[6] Bloom, B., The Two Sigma Problem: The search for Methods of Group Instruction as Effective as One-to-One Tutoring Educational Researcher, 1984

[7] Karweit, N., Time on Task, Reconsidered, Synthesis of Research on Time and Learning, Educational Leadership, 1984.

[8] www.prezi.com

[9] www.beedocs.com

[10] www.khanacademy.org

[11] Kuznekoff. J. H. and Titsworth, S. (2013). The impact of mobile phone usage on student learning. Communication Education, 62 (3), 233-252.

[12] Kraushaar, J. M. and Novak, D. C. (2010). Examining the affects of student multitasking with laptops during lecture. Journal of Information Systems Education, 21 (2), 241-251.

[13] Barak, L. (2012). Multitasking in the university classroom. International Journal for the Scholarship of Teaching and Learning, 6 (2).

[14] Ellis, Y., Daniels, W. and Jauregui, A. (2010). The effect of multitasking on the grade performance of business students. Research in Higher Education Journal, 8

[15] Fried, C. B. (2008). In-class laptop use and its effects on student learning. Computers and Education, 50 (3), 906. 
Proc. 2014 Canadian Engineering Education Association (CEEA14) Conf.

[16] Schofield, C., Honore, S., Generation Y and learning, The Ashridge Journal, 2009/2010.

[17] Fun with Class Size Data, http://higheredstrategy.com/category/class-size/ 